Article

\title{
Inhibition of Campylobacter jejuni Biofilm Formation by D-Amino Acids
}

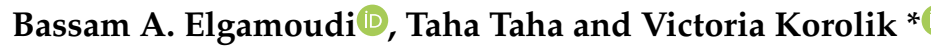 \\ Institute for Glycomics, Griffith University, Gold Coast QLD 4222, Australia; \\ b.elgamoudi@griffith.edu.au (B.A.E.); Taha@griffith.edu.au (T.T.) \\ * Correspondence: v.korolik@griffith.edu.au
}

Received: 30 September 2020; Accepted: 20 November 2020; Published: 23 November 2020

\begin{abstract}
The ability of bacterial pathogens to form biofilms is an important virulence mechanism in relation to their pathogenesis and transmission. Biofilms play a crucial role in survival in unfavorable environmental conditions, acting as reservoirs of microbial contamination and antibiotic resistance. For intestinal pathogen Campylobacter jejuni, biofilms are considered to be a contributing factor in transmission through the food chain and currently, there are no known methods for intervention. Here, we present an unconventional approach to reducing biofilm formation by $C$. jejuni by the application of D-amino acids (DAs), and L-amino acids (LAs). We found that DAs and not LAs, except L-alanine, reduced biofilm formation by up to $70 \%$. The treatment of $C$. jejuni cells with DAs changed the biofilm architecture and reduced the appearance of amyloid-like fibrils. In addition, a mixture of DAs enhanced antimicrobial efficacy of D-Cycloserine (DCS) up to $32 \%$ as compared with DCS treatment alone. Unexpectedly, D-alanine was able to reverse the inhibitory effect of other DAs as well as that of DCS. Furthermore, L-alanine and D-tryptophan decreased transcript levels of peptidoglycan biosynthesis enzymes alanine racemase (alr) and D-alanine-D-alanine ligase $(d d l A)$ while D-serine was only able to decrease the transcript levels of alr. Our findings suggest that a combination of DAs could reduce biofilm formation, viability and persistence of $C$. jejuni through dysregulation of alr and ddlA.
\end{abstract}

Keywords: D-amino acids; Campylobacter jejuni; biofilm; alanine racemase; confocal laser scanning microscopy

\section{Introduction}

Human pathogen Campylobacter jejuni is a leading foodborne bacterial cause of diarrheal disease which, according to the World Health Organization (WHO), occurs annually in approximately $10 \%$ of the world's population, including 200 million children [1,2]. Campylobacters are increasingly resistant to antibiotics; this is enhanced by their ability to form biofilms [3-6]. C. jejuni, in particular, is able to form mono- and mixed-culture biofilms in vitro and in vivo [7], which is recognized as a contributing factor of $C$. jejuni transmission through the food chain, where biofilms allow the cells to survive up to twice as long under atmospheric conditions and in water [8-10]. Campylobacters exhibit intrinsic resistance to many antimicrobial agents such as cephalosporins, trimethoprim, sulfamethoxazole, rifampicin and vancomycin, and are listed in WHO list of priority pathogens for new antibiotics development $[3,4,11-16]$. Biofilms are known to enhance antimicrobial resistance of many pathogens [3-5,17]; thus, unconventional approaches to controlling biofilms and improving the efficacy of currently used antibiotics are urgently needed. Recent investigations into potential antimicrobials include naturally occurring small molecules such as nitric oxide, fatty acids, and D-amino acids (DAs) [18-21]. DAs showed an ability to disperse some bacterial biofilms in vitro, such as those formed by Bacillus subtilis, Staphylococcus aureus, Enterococcus faecalis and Pseudomonas aeruginosa [22-26]. It is 
well documented that microorganisms preferentially utilize L-amino acids (LAs) over DAs [27,28], yet naturally occurring DAs have been found in different environments, such as soil, as well as in human and animals tissues [27]. In addition, many bacterial species secrete DAs in the stationary growth phase and when encased in biofilms. For example, Vibrio cholerae can produce D-methionine (D-met) and D-leucine (D-leu), while B. subtilis generates D-tyrosine (D-tyr) and D-phenylalanine (D-phe) which can accumulate at millimolar concentrations [29,30]. The ability of bacteria to produce DAs is proposed to be a mechanism for self-dispersal of aging biofilms, and DA production may also inhibit the growth of other bacteria during maturation of mixed biofilms. In a naturally occurring biofilm, DAs are found to be involved in the regulation of extracellular polymeric saccharide (EPS) production, for instance, D-tyr reduces the attachment of B. subtilis, S. aureus and P. aeruginosa to surfaces [23,31-33]. Also, DAs can induce disassembly of matrix-associated amyloid fibrils that link cells within the biofilm and contribute to the biofilm strength [34]. The effective concentration of DAs required to inhibit the biofilm formation varies depending on bacterial strain and DAs concentration ranging between $3 \mu \mathrm{M}$ and $10 \mathrm{mM}$ and D-Met, D-Trp and D-Ser were shown the most potent to inhibit the biofilm formation $[24,33,35,36]$. It is important to note that some DAs exhibit inhibitory or toxic effects on a number of bacterial species and can interfere with the activities of peptidases and proteases involved in cell wall synthesis, for example, D-met can be incorporated into the peptidoglycan (PG) of bacterial cell walls, causing morphological and structural damage [37].

DAs appear to be able to disrupt the biofilms via multiple mechanisms, offering an advantage to other biofilm dispersal agents which target a single process essential for biofilm formation, indicating that DAs could form the basis for a potential antibiofilm agent.

This study explores the effect of D and L amino acids, singly and in combination, on inhibition and dispersion of $C$. jejuni biofilms, the ability of these compounds to enhance the efficacy of antibiotics such D-cycloserine as well as potential mechanisms of inhibitory action.

\section{Results}

\subsection{Effect of LAs and DAs on Biofilm Formation by C. jejuni}

In order to investigate the effect of LAs and DAs on biofilm formation, different concentrations of LAs and DAs (1-100 mM) were tested for their ability to disrupt or disperse the Campylobacter biofilm. Two assays were applied, one to measure the percentage of biofilm inhibition (\%) (Inhibition Assay) and the other to determine the effect on the dispersion of a formed biofilm (Dispersion Assay). Treatment of $C$. jejuni culture with DAs showed significant inhibitory effect $(p<0.001)$ on biofilm formation. Prescreening of individual LAs and DAs identified four (D-ala, D-met, D-ser, and D-trp) that had a potent ability to inhibit biofilm formation by C. jejuni (Figure 1). In contrast, the L-form of those amino acids, except L-ala, had no inhibitory effect, and L-met and L-trp, significantly increased biofilm formation.

The addition of DAs had a strong inhibitory effect on biofilm formation by C. jejuni in a dose-dependent manner (Figure 2) where $10 \mathrm{mM}$ of D-trp reduced biofilm formation by $48 \%$ and $25 \mathrm{mM}$ by $52 \%$, while $10 \mathrm{mM}$ and $25 \mathrm{mM}$ D-ala reduced biofilm formation by $28 \%$ and $32 \%$, respectively. Interestingly, $50 \mathrm{mM}$ L-ala reduced biofilm by up to $63 \%$ as compared to $45 \%$ by D-ala at the same concentration (Figure 2). DAs had a disruptive effect on the existing biofilm where D-ser had the most significant effect $(p<0.001)$ on formed biofilm disruption, up to $71 \%$, at $50 \mathrm{mM}$ compared to $1 \mathrm{mM}$ or $10 \mathrm{mM}$ (Figure 2), and the addition of $10 \mathrm{mM}$ D-trp led to $42 \%$ disruption of formed biofilm.

Based on the determined concentrations of DAs required to elicit inhibitory or dispersal effect on biofilms, concentrations of various DAs and LAs between 2 to $25 \mathrm{mM}$ were selected for subsequent assays. 


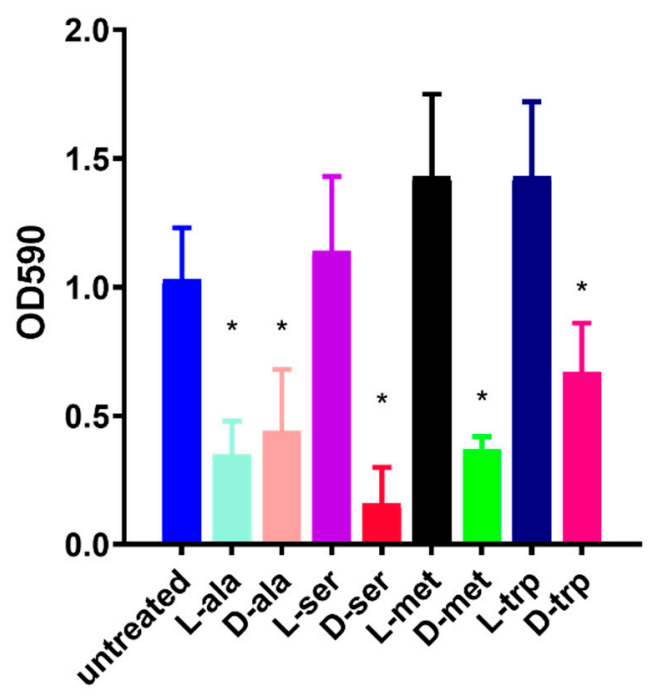

Figure 1. Effect of $100 \mathrm{mM}$ D-amino acids (DAs) and L-amino acids (LAs) on C. jejuni 11168-O biofilm. Inhibition of biofilm formation in the presence of $100 \mathrm{mM}$ of; L-alanine (L-ala), D-alanine (D-ala), L-serine (L-ser), D-serine (D-ser), L-methionine (L-met), D-methionine (D-met), L-tryptophan (L-trp), or D-tryptophan (D-trp). All data are mean \pm Standard errors and were analyzed using an unpaired, two-tailed Student's $t$-test, $p<0.05$. The asterisk $\left(^{*}\right)$ indicates a statistically significant difference compared to untreated control.

A

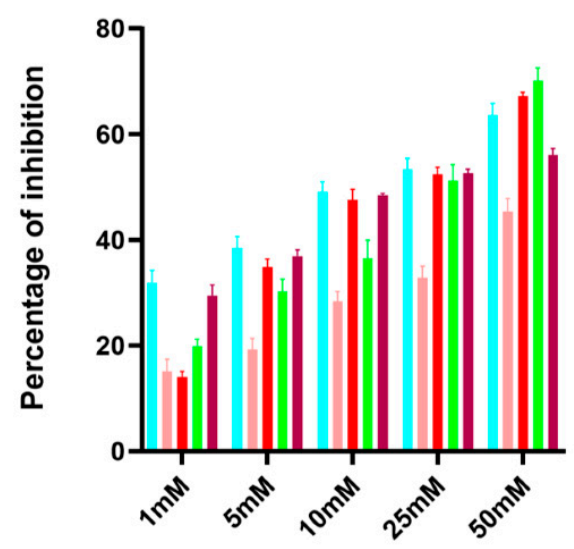

B

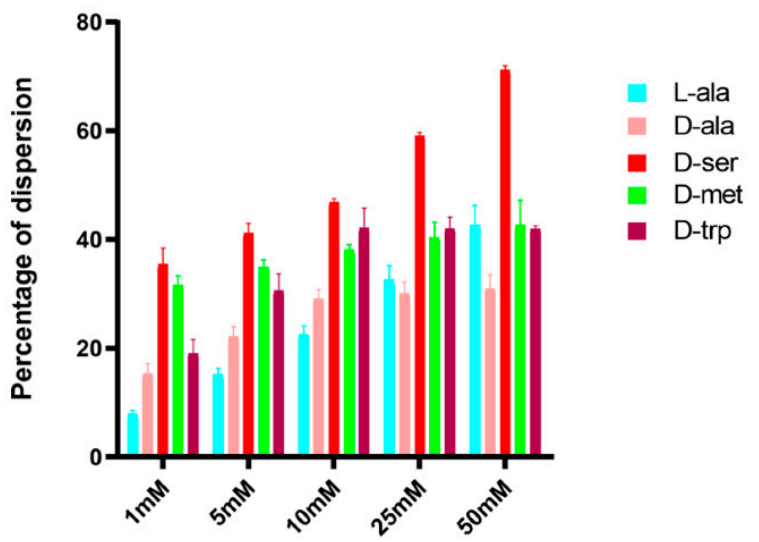

Figure 2. Inhibition and dispersion response of $C$. jejuni 11168-O biofilms in the presence of LAs and DAs at different concentrations. (A) Inhibition of biofilm formation by different concentrations of LAs and DAs, (B) Dispersion of the existing biofilm induced by different concentrations of LAs and DAs. The data is presented as Mean \pm Standard errors of Percentage of inhibition (Normalized to untreated control).

\subsection{Effect of DAs on Biofilm Formation by Different Campylobacter Strains}

In order to elucidate strain-specific responses, C. jejuni 11168-O, C. jejuni 81-176, and C. coli NCTC 11366, were used to confirm the inhibitory effect of D-ala, D-ser, D-met, and D-trp at $10 \mathrm{mM}$. The effect of DAs on biofilm formation was strain-dependent, whereas D-ser and D-trp had the greatest inhibitory effect on biofilm formation by 11168-O, D-ala and D-met were most effective against 81-176, and C. coli (Figure 3). 

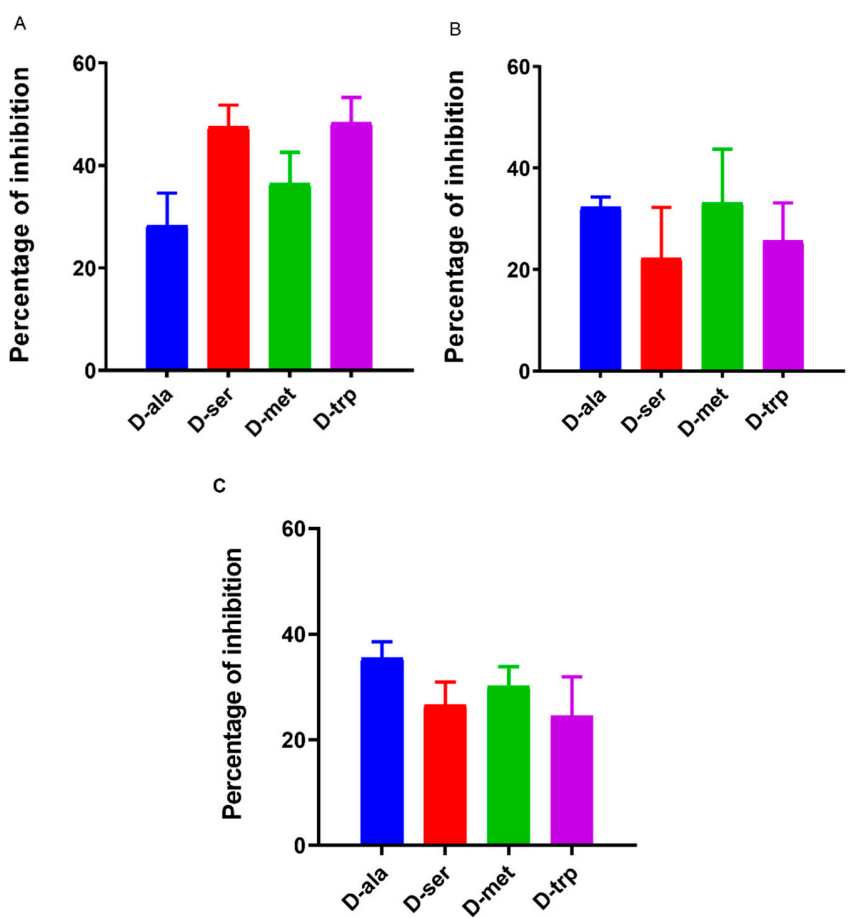

Figure 3. Quantitative analysis of biofilm inhibition of (A) C. jejuni 11168-O, (B) C. jejuni 81-176, and (C) C. coli NCTC 11366 in the presence of $10 \mathrm{mM}$ of DAs. The data is presented as Mean \pm Standard errors of Percentage of inhibition (Normalized to untreated control).

\subsection{Effect of the Equimolar Mixture of DAs and LAs on C. jejuni 11168-O Biofilm}

Considering that D-ser or D-met, applied at $>1 \mathrm{mM}$ concentration, induced biofilm dispersal, while $5 \mathrm{mM}$ L-ala, D-ser, D-met or D-trp had an inhibitory effect, equimolar mixture of DAs and LAs (1:1) was assessed. Equimolar mixture showed $\geq 40 \%$ inhibition of $C$. jejuni 11168 -O biofilm formation (Figure 4). This suggested that using a combination of DAs and LAs, even at lowest concentrations, could be more potent than application of single DA or LA. The mixture of the four amino acids, L-ala, D-met, D-ser, D-trp was therefore assessed and a combination of these amino acids at 5:5:2:5 $\mathrm{mM}$ was more effective, with up to $49 \%$ inhibition of biofilm formation. Interestingly, the addition of D-ala decreased this inhibitory effect (Figure 4).

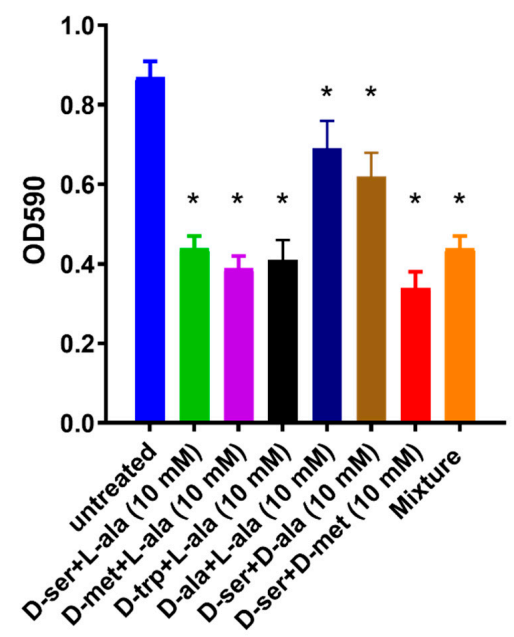

Figure 4. Effect of the equimolar mixture of DAs and LAs on C. jejuni 11168-O biofilm. All data are mean \pm Standard errors and were analyzed using an unpaired, two-tailed Student's $t$-test, $p<0.05$. The asterisk $\left(^{*}\right)$ indicates a statistically significant difference compared to untreated control. 


\subsection{Microscopic Characterization of the Dispersion Effect of DAs on Biofilm}

Confocal microscopy showed that mature biofilm of C. jejuni 11168-O has structured appearance with amyloid-like fibrils which connect the cells within biofilms (Figure 5).

DAPI

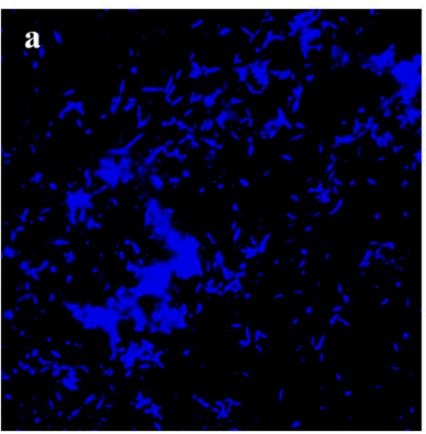

ThT

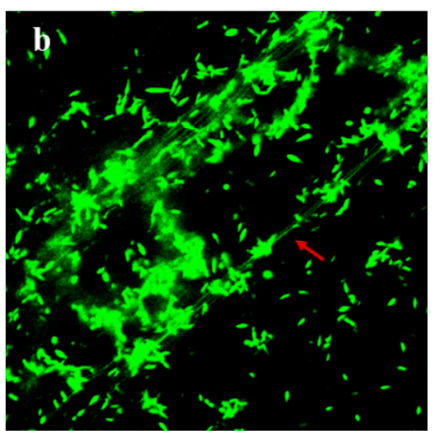

Merged

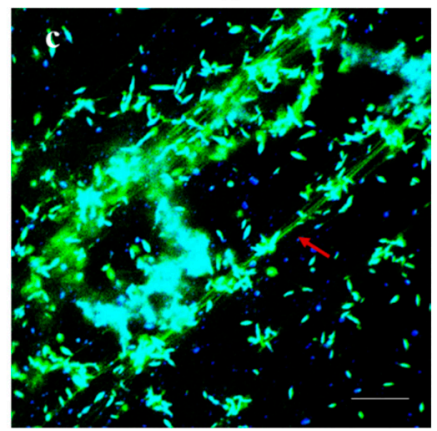

Figure 5. The mature biofilm of $C$. jejuni $11168-O$ and amyloid-like fibres. C. jejuni biofilm imaged using dual fluorescence labelling by confocal laser scanning microscopy (CLSM). (a-c) Bacterial cells within the biofilm (4',6-diamidino-2-phenylindole (DAPI), blue) and red arrow indicates for amyloid-like fibrils (Thioflavin $\mathrm{T}$ (ThioT), green). (Scale bar $=10 \mu \mathrm{m})$.

Microscopic examination of formed biofilms, treated with individual DAs, showed a significant reduction in biofilm formation and disappearance of amyloid-like fibrils, compared to that of untreated controls (Figure 6).
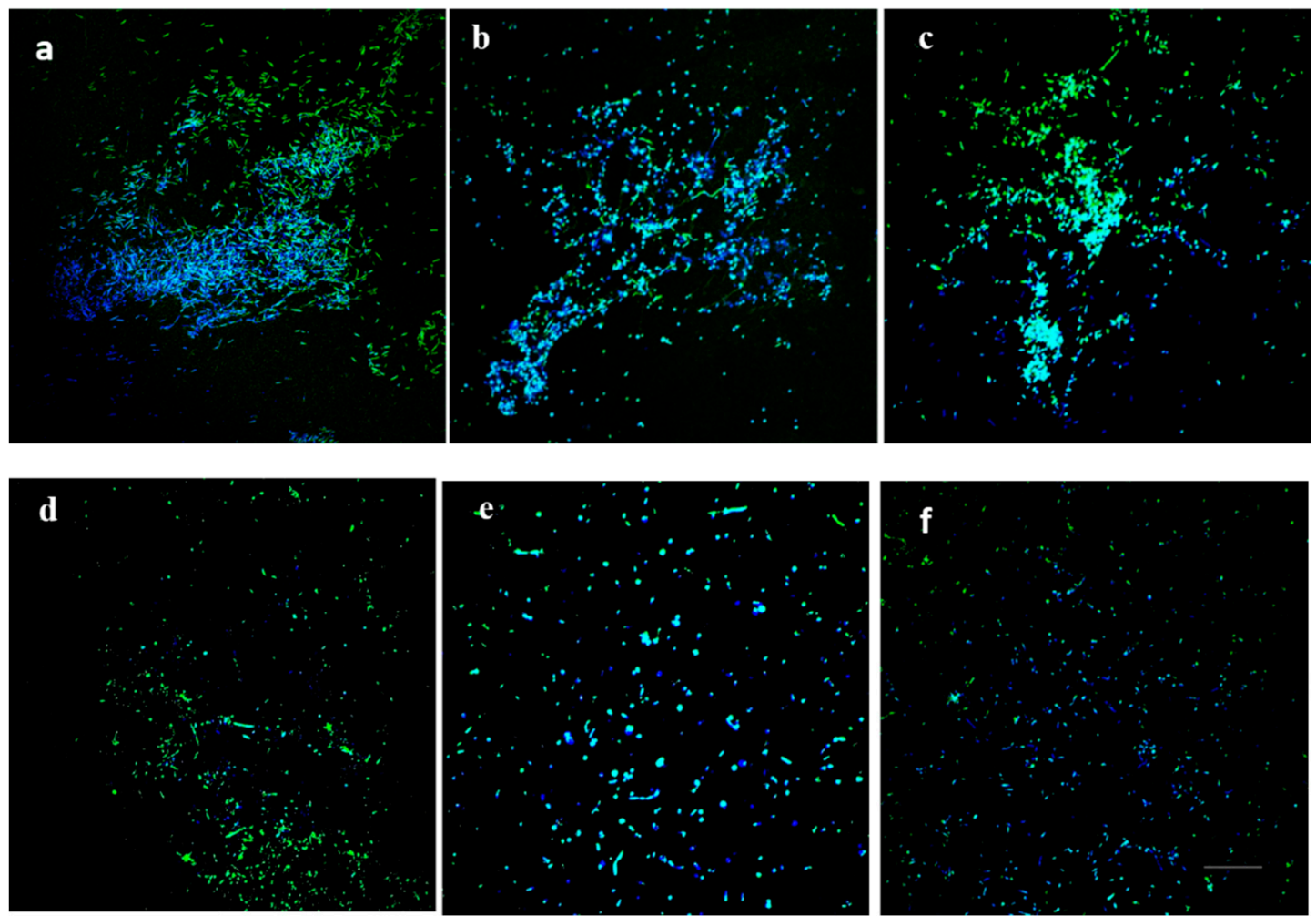

Figure 6. Confocal scanning laser microscopy images of C. jejuni 11168-O biofilm in presence of $25 \mathrm{mM}$ of DAs. C. jejuni biofilm at $48 \mathrm{~h}$, imaged using dual fluorescence labelling by confocal laser scanning microscopy (CLSM). (a) Untreated, (b) D-ala, (c) L-ala, (d) D-ser, (e) D-met, (f) D-trp. Cells were stained with $4^{\prime}$,6-diamidino-2-phenylindole (DAPI, blue) and amyloid fibrils by Thioflavin $\mathrm{T}$ (ThioT, green) $($ Scale bar $=20 \mu \mathrm{m})$. 


\subsection{Expression Level of alr and ddlA in the Presence of LAs and DAs}

In order to interrogate the mechanism of inhibitory action of DAs and L-ala, the expression of C. jejuni PG biosynthesis enzymes alanine racemase (alr) and D-Ala-D-Ala ligase $(d d l A)$ in the presence and absence of DAs and LAs were examined. Therefore, $25 \mathrm{mM}$ of DAs and LAs was chosen based on the inhibitory effects as shown in Figure 2. The relative expression of $d d l$ and alr was downregulated by 1.25 to 4 -fold below the cut-off level, respectively, following treatment of cells with $25 \mathrm{mM}$ of L-ala (Table 1). In contrast, $25 \mathrm{mM}$ of D-ala upregulated the expression of $d d l$ by 10 -fold and alr by 38 -fold. Treatment of cells with $25 \mathrm{mM}$ D-trp downregulated the expression level of $d d l$ by 1.65 -fold and alr by 3-fold whereas D-ser ( $25 \mathrm{mM}$ ) downregulated the expression of alr by 2.92-fold and upregulated ddl by 2.58-fold. No significant effect on the expression of $a l r$ and $d d l$ was observed following treatment with D-met (Table 1). Interestingly, treatment of cells with D-Cycloserine (DCS) (10 ng/mL), as a positive control, had a greater effect, downregulating the expression of $d d l A$ with a 7 -fold change as compared to 2.85 -fold change for alr. No loss of cell viability could be detected after $2 \mathrm{~h}$ exposure to DAs or DCS.

Table 1. Analysis of the relative expression of alr and $d d l A$ genes in the present of LAs and DAs by real-time PCR (RT-PCR). The relative expression of alr and $d d l$ genes after incubation of $C$. jejuni 11168-O cells with $25 \mathrm{mM}$ of LAs and DAs for $2 \mathrm{~h}$.

\begin{tabular}{cccccccc}
\hline & \multicolumn{7}{c}{ Fold Change } \\
\cline { 2 - 8 } & \multicolumn{7}{c}{ Upregulated } \\
Gene Name & D-ala & D-ser & D-met & L-ala & D-ser & D-trp & DCS \\
\hline$a l r$ & $38 \pm 7$ & - & - & $4.18 \pm 0.3$ & $2.92 \pm 0.2$ & $1.65 \pm 0.3$ & $2.85 \pm 0.2$ \\
\hline$d d l A$ & $10 \pm 2$ & $2.58 \pm 0.6$ & - & $1.25 \pm 0.1$ & - & $3.42 \pm 0.4$ & $7.15 \pm 0.2$ \\
\hline
\end{tabular}

\subsection{D-Ala Can Reverse the Inhibitory Effect of DAs and DCS}

D-ala has been reported to reverse the antimicrobial efficacy of DCS in Mycobacterium spp. [38,39]. Considering that the minimum inhibitory concentration (MIC) range of DCS for Campylobacter spp reported being between $0.25-4 \mu \mathrm{g} / \mathrm{mL}$ [40], we tested the effect of sub-inhibitory concentration of 10-50 ng/mL DCS on C. jejuni cells and determined that DCS can reduce C. jejuni growth and biofilm formation by up to $60-76 \%$ (Figures 7 and 8 ). Furthermore, this effect can be reversed by increasing the concentration of D-ala from $10 \mathrm{mM}$ to $50 \mathrm{mM}$ (Figure 7A). Combining D-ala with D-ser or with L-ala also decreased the inhibition of biofilm formation (Figure 7B). In contrast, a combination of DAs with DCS increased the efficacy of DCS at $10 \mathrm{ng} / \mathrm{mL}$ by $32 \%$ as compared with DCS treatment alone (Figure 8).

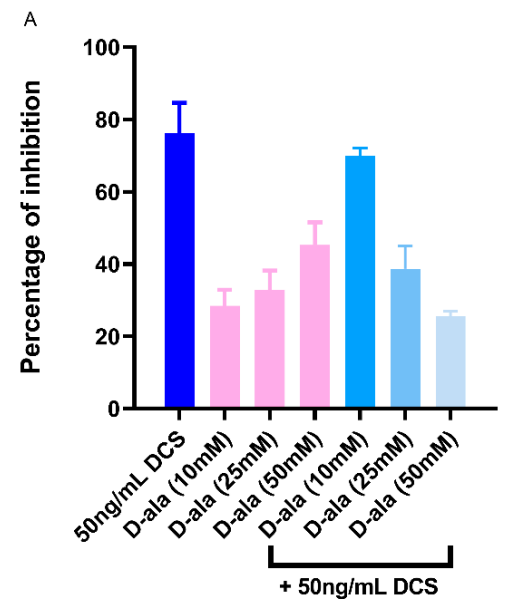

Figure 7. Cont. 


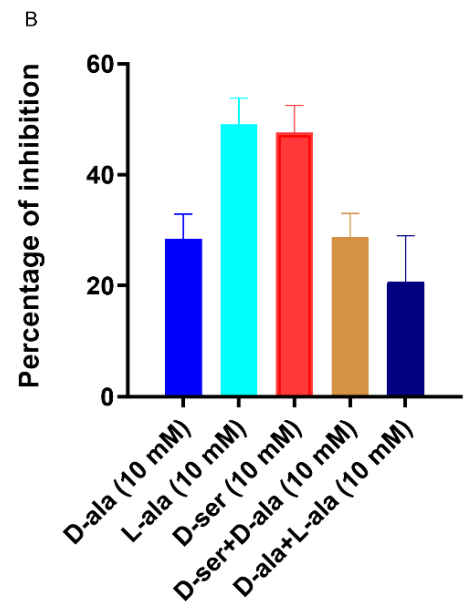

Figure 7. Reversal of C. jejuni 11168-O biofilm inhibition by (A) D-Cycloserine (DCS), (B) L-ala and $\mathrm{D}$-ser in presence of D-alanine (D-ala). The data is presented as Mean \pm Standard errors of Percentage of inhibition (Normalized to untreated control).

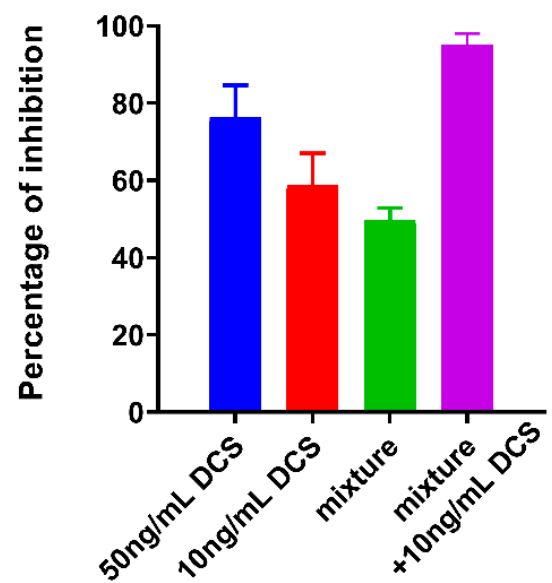

Figure 8. Effect of DCS on C. jejuni 11168-O biofilm when combined with a mixture of L-ala, D-ser, D-met, D-trp (5:5:2:5 mM). The data is presented as Mean \pm Standard errors of Percentage of inhibition (Normalized to untreated control).

\section{Discussion}

This study describes the activity of specific small, naturally occurring molecules, DAs, which are highly effective in preventing and disrupting $C$. jejuni biofilms, in concert with that previously shown for B. subtilis, S. aureus and P. aeruginosa $[36,41]$. While D-met and D-trp were able to inhibit the biofilm formation of $C$. jejuni, L-form of those amino acids significantly increased biofilm formation. It is possible that $C$. jejuni is able to catabolize L-form of those amino acids [42], which promotes bacterial growth, and consequently formation of the biofilm. This is consistent with the previous report of B. subtilis growth inhibition by D-form of Tyr, Leu, and Trp, and the L-form of those amino acids counteracting this effect [24]. The effect of DAs on inhibition and dispersal of $C$. jejuni biofilms showed a concentration-dependent response, with D-ser, D-met and D-trp being most effective in inhibition and dispersion of the biofilm. We observed that D-met, and D-trp, have a significant effect on triggering the disassembly of the biofilms at concentrations of $\geq 5 \mathrm{mM}$, similar to that observed for S. aureus and P. aeruginosa [43]. It is important to note that the inhibitory effect on the growth of $C$. jejuni by DAs, except D-met, could be reversed by D-ala, similar to that observed for B. subtilis, M. tuberculosis and Escherichia coli $[38,39,44,45]$.

The microscopic analysis confirmed the effect of DAs on biofilm formation of C. jejuni, and particularly, the formation of amyloid-like fibrils within the biofilm matrix. Matrix-associated 
amyloid fibrils had been previously reported to form a part of C. jejuni biofilm [46], and similar DA-induced disassembly of matrix-associated amyloid fibers of B. subtilis biofilm, had been proposed as a biofilm-dispersal mechanism [34,41]. Together, these data allow us to speculate that the ability of DAs to promote the dispersal of formed C. jejuni biofilms, could involve the triggering the disassembly of matrix-associated amyloid fibrils.

While the mechanisms of antimicrobial and antibiofilm action of DAs, particularly, D-ser, D-met, and D-trp, are not fully understood, DAs effect on C. jejuni growth and biofilm formation may be similar to that for Alcaligenes faecalis, where D-met incorporates into PG, causing morphological and structural damage to the cell wall $[30,37,47]$, and consequently suppresses bacterial growth. To explore that possibility, we interrogated the effect of DAs and LAs on the expression level of two genes in C. jejuni; alanine racemase (alr) (Cj0905c), and D-Ala-D-Ala ligase (ddlA) (Cj0798c) [48,49]. Both genes are encoding enzymes involved in an important step in D-Ala metabolism [44,50], which is essential for the synthesis of PG of the bacterial cell wall $[45,51,52]$. Two main reactions are involved in this process, first the conversion of L-Ala to D-Ala by alanine racemase (alr), and the formation of D-alanyl-D-alanine dipeptide (D-Ala-D-Ala) from D-ala by D-alanine-D-alanine ligase (ddl) [53]. RT-PCR data showed that DCS was able to reduce both $C$. jejuni alr and $d d l A$ expression levels, similarly to L-ala, and D-trp. Interestingly, D-ser reduced alr expression levels, but not that of $d d l A$, suggesting that $d d l A$ may not be the primary target for D-ser or DCS in C. jejuni. Furthermore, the ability of D-ala to reverse the inhibitory effect of DCS and D-ser suggests that the inhibitory effect of DCS and D-ser on C. jejuni can be mediated through inhibition of alr alone. In contrast, in $M$. tuberculosis, both alr and $d d l$ were reported to be the primary targets of DCS [39], and Halouska et al. [54] suggested that $d d l$ may be a primary target of DCS, rather than alr.

It is interesting to note that bacterial PG dipeptide D-Ala-D-Ala, which is generated by D-Ala-D-Ala ligase $(d d l A)$, is the usual target for vancomycin, but in C. jejuni, PG contains D-Alanyl-D-Lactate (D-Ala-D-Lac) termini resulting in reduced efficacy of vancomycin by up to 1000-fold. Substitution by D-alanyl-D-serine (D-Ala-D-ser) termini reduces the efficacy of this antibiotic by up to 7-fold [4,55-58]. This further suggests that alr and not $d d l A$, is likely to be the primary target for D-ser and DCS in C. jejuni.

Our results suggest that DAs might have a promising application in enhancing of the activity antibiotics where the combination of DAs with DCS, synergistically increased the ability of DCS to inhibit C. jejuni biofilm formation and growth. The enhancement of DCS efficacy with DAs is likely to lower minimal dose requirement, which would consequently reduce the drug toxicity. DAs had also been reported to enhance the effectiveness for colistin and ciprofloxacin, when used against biofilms of $P$. aeruginosa, and rifampin used against biofilms of clinical isolates of S. aureus [43].

Here we have, therefore, demonstrated that D-alanine (D-ala),L-alanine (L-ala), D-serine (D-ser), D-methionine (D-met), and D-tryptophan (D-trp) can inhibit and disperse biofilms formed by C. jejuni and C. coli and that it may be possible to use these DAs to enhance the efficacy of antibiotics such D-cycloserine. Also, we presented evidence that DAs target alanine racemase (alr) in C. jejuni, which leads to the inhibition of growth and biofilm formation. This finding may be the key to understanding the mechanisms of DAs action and also could provide an alternative strategy to control Campylobacter spp transmission via the food chain.

\section{Materials and Methods}

\subsection{C. jejuni Strains and Growth Conditions}

Bacterial strains used in this study were C. jejuni 11168-O (courtesy of Prof. D. G. Newell, Guildford, UK), C. jejuni 81-176 (courtesy of Prof. Christine Szymanski, University of Alberta, Edmonton, AB, Canada), and C. coli NCTC 11366 (Griffith University culture collection, Gold Coast, Australia). Cells were grown at $42{ }^{\circ} \mathrm{C}$ microaerobically $\left(85 \% \mathrm{~N}_{2}, 10 \% \mathrm{CO}_{2}\right.$ and $\left.5 \% \mathrm{O}_{2}\right)$ on Mueller-Hinton agar (MHA) and in Mueller-Hinton broth (MHB), supplemented with Trimethoprim $\left(5 \mu \mathrm{g} \mathrm{mL} \mathrm{L}^{-1}\right)$ and 
Vancomycin $\left(10 \mu \mathrm{g} \mathrm{mL}^{-1}\right)$ (TV) (Sigma-Aldrich, Saint Louis, MO, USA). Microaerobic conditions were established by using Oxoid CampyGen (Thermo Scientific, Scoresby, Australia).

\subsection{Chemical and Reagents Used in this Study}

L-alanine (L-ala), D-alanine (D-ala), L-serine (L-ser), D-serine (D-ser), L-methionine (L-met), D-methionine (D-met), L-tryptophan (L-trp), D-tryptophan (D-trp) D-cycloserine were purchased from Sigma-Aldrich, Saint Louis, MO, USA. Individual stock solutions of $100 \mathrm{mM}$ of DAs were prepared in Phosphate-buffered saline (PBS) (pH 7.2).

\subsection{Biofilm Formation and Dispersion Assays}

Overnight cultures of $C$. jejuni strains were diluted to an $\mathrm{OD}_{600}$ of 0.05 , and $2 \mathrm{~mL}$ of cell suspension were dispersed into 24-wells flat-bottom polystyrene tissue culture plates (Geiner Bio-One, Monroe, NC, USA). Different concentrations of DAs (1-100 mM) were added directly to the culture in the wells and incubated at $42{ }^{\circ} \mathrm{C}$ under microaerobic conditions for $48 \mathrm{~h}$. For dispersion assay, C. jejuni cells were grown as described above, except no DAs were added. Then PBS containing the appropriate concentration of DAs (1-100 mM) was added to the wells and plates incubated for further $24 \mathrm{~h}$. For crystal violet staining, plates were rinsed with water once (gently), dried at $55{ }^{\circ} \mathrm{C}$ for $30 \mathrm{~min}$ and stained using modified crystal violet staining method as described previously [59]. Data are representative of three independent experiments, and values are presented as Mean \pm Standard errors. The percentage of biofilm inhibition and dispersion $(\%)$ was calculated as described in $[60,61]$ by the following formula:

$$
\%=\left(\text { control }^{\mathrm{OD} 590 \mathrm{~nm}}-\text { test }^{\mathrm{OD} 590 \mathrm{~nm}} / \text { control }^{\mathrm{OD} 590 \mathrm{~nm}}\right) \times 100 .
$$

\subsection{RNA Extraction, cDNA Synthesis and RT-qPCR of Alanine Racemase (alr), D-alanine-D-alanine Ligase (ddlA)}

C. jejuni $11168-\mathrm{O}$ cells were grown overnight microaerobically in $\mathrm{MHB}$ at $42{ }^{\circ} \mathrm{C}$. Cells were collected by centrifuging at $4000 \mathrm{rpm}$ for $15 \mathrm{~min}$. The pellets were suspended in $\mathrm{MHB}$ and $\mathrm{OD}_{600}$ adjusted to $1\left(\sim 3 \times 10^{9}\right.$ cells $\left./ \mathrm{mL}\right)$ and subsequently challenged with (1) $25 \mathrm{mM}$ of L-ala, (2) $25 \mathrm{mM}$ of D-ala, (3) $25 \mathrm{mM}$ of D-ser, (4) $25 \mathrm{mM}$ of D-met or, (5) $25 \mathrm{mM}$ of D-trp for $2 \mathrm{~h}$; (5) $10 \mathrm{ng} / \mathrm{mL}$ of DCS (below MIC which $250 \mathrm{ng} / \mathrm{mL}$ ) was used as control. The bacterial survival was confirmed by viable cells counts after $2 \mathrm{~h}$. Then, cells were collected by centrifugation at $4000 \mathrm{rpm}$ for $15 \mathrm{~min}$ and pellets used for RNA extraction by RNeasy kit according to the manufacturer's protocol (Bioline, Eveleigh, Australia). cDNA synthesis and RT-qPCR were performed as previously described [62]. The following primers sets were used: alr (Cj0905c) forward 3-AGCCAAAAATTTAGGAGTTT-5 and alr reverse 5-GAGGACGATGTGATAGTATT-3, $d d l$ (Cj0798c) forward 3-TTATTTTTTGTGATGAAGAAAGAA-5 and $s d l$ reverse 5-GAGTTCTTTTTCTTTTTTATAAGC-3. A gryA gene was used as a housekeeping control gene, using the primers, gryA forward 3-CCACTGGTGGTGAAGAAAATTTA- 5 and gry $A$ reverse 5-AGCATTTTACCTTGTGTGCTTAC-3. Relative $n$-fold changes in the transcription of the examined genes between the treated and non-treated samples were calculated using the relative quantification (RQ), also known as $2^{-\Delta \Delta C T}$ method, where $\Delta \Delta C_{T}=\Delta C_{T}$ (treated sample) $-\Delta C_{T}$ (untreated sample), $\Delta C_{T}=C_{T}$ (target gene) $-C_{T}\left(\right.$ gyr $A$ ), and $C_{T}$ is the threshold cycle value for the amplified gene. The fold change due to treatment was calculated as $-1 / 2^{-\Delta \Delta C T}[63,64]$. The data are presented as Mean \pm S.D and were calculated from triplicate cultures and are representative of three independent experiments.

\subsection{Confocal Laser Scanning Microscopy}

Overnight cultures of $C$. jejuni cells were diluted to an $\mathrm{OD}_{600}$ of 0.05 , and $3 \mathrm{~mL}$ of each sample was placed into duplicate wells of a 6-well flat-bottom polystyrene tissue culture plate containing a glass coverslip to enable the formation of biofilm (Geiner Bio-One, Monroe, NC, USA). Thus, $25 \mathrm{mM}$ of LAs 
and DAs were added directly to the wells, and then the plates were incubated at $42{ }^{\circ} \mathrm{C}$ microaerobically for $48 \mathrm{~h}$. After the incubation, MH broth was removed, and the wells were gently washed with PBS solution twice to remove planktonic cells. The coverslips were carefully removed by using sterile needle and forceps to new 6-well plates and fixed using 5\% formaldehyde solution for $1 \mathrm{~h}$ at room temperature. Then, the coverslips were gently washed with $2 \mathrm{~mL}$ of PBS and prepared for staining with fluorescent dyes.

\subsection{Staining of C. jejuni Cells}

The fluorescent DNA-binding stain DAPI (Sigma Aldrich, Saint Louis, MO, USA) was used to visualize cell distribution as described previously [65]. Thioflavin T (ThT) (Sigma Aldrich, Saint Louis, $\mathrm{MO}, \mathrm{USA}$ ) at $20 \mu \mathrm{M}$ was then used to treat the coverslips for $30 \mathrm{~min}$. ThT emits green fluorescence upon binding to cellulose or amyloids $[66,67]$. The coverslips then were mounted on glass slides using the mounting medium (Ibidi GmbH, Martinsried, Germany) and sealed with transparent nail varnish. Microscopy (Nikon A1R+) (Griffith University) was performed with two coverslips per sample from at least two separate experiments. All images were processed using ImageJ analysis software version $1.5 \mathrm{i}$ (National Institutes of Health, Bethesda, MD, USA).

\subsection{Statistical Analysis}

Statistical significance of data generated in this study was determined using two tailed Student's $t$-test, GraphPad Prism (GraphPad Software version 8.0.0 for Windows, GraphPad Software, San Diego, CA, USA). $p \leq 0.05$ was considered statistically significant.

\section{Conclusions}

To summarize, this study suggests that (i) DAs show the inhibitory effect at millimolar concentrations on biofilm formation by C. jejuni; (ii) DAs can trigger C. jejuni biofilm-disassembly; (iii) a combination of DAs can enhance the efficacy of DSC,(iv) DAs inhibit growth and biofilm formation of $C$. jejuni by repressing the expression of alr. The data described here contribute to the understanding of the mechanisms involved in biofilm dispersion and inform on identification of potential antimicrobial drug targets.

Author Contributions: V.K. and B.A.E. conceived and designed the study; B.A.E. and T.T. performed the experiments; V.K. and B.A.E. analyzed the data and prepared the manuscript. All authors have read and agreed to the published version of the manuscript.

Funding: This project was partially supported by Griffith University, Institute for Glycomics.

Acknowledgments: The authors thank Neeraj Bhatnagar and Michael Hadjistyllis for technical assistance.

Conflicts of Interest: Authors declare that there is no conflict of interest regarding the publication of this article.

\section{References}

1. Grantham-McGregor, S.; Cheung, Y.B.; Cueto, S.; Glewwe, P.; Richter, L.; Strupp, B. Developmental potential in the first 5 years for children in developing countries. Lancet 2007, 369, 60-70. [CrossRef]

2. World Health Organization. The Global View of Campylobacteriosis: Report of an Expert Consultation. Utrecht, Netherlands, 9-11 July 2012. Available online: https://apps.who.int/iris/handle/10665/80751 (accessed on 20 November 2020).

3. Luangtongkum, T.; Jeon, B.; Han, J.; Plummer, P.; Logue, C.M.; Zhang, Q. Antibiotic resistance in Campylobacter: Emergence, transmission and persistence. Futur. Microbiol. 2009, 4, 189-200. [CrossRef] [PubMed]

4. Iovine, N.M. Resistance mechanisms in Campylobacter jejuni. Virulence 2013, 4, 230-240. [CrossRef] [PubMed]

5. Engberg, J. Quinolone and Macrolide Resistance in Campylobacter jejuni and Campylobacter coli: Resistance Mechanisms and Trends in Human Isolates. Emerg. Infect. Dis. 2001, 7, 24-34. [CrossRef] 
6. Bae, J.; Oh, E.; Jeon, B. Enhanced transmission of antibiotic resistance in Campylobacter jejuni biofilms by natural transformation. Antimicrob. Agents Chemother. 2014, 58, 7573-7575. [CrossRef]

7. Ica, T.; Caner, V.; Istanbullu, O.; Nguyen, H.D.; Ahmed, B.; Call, D.R.; Beyenal, H. Characterization of Monoand Mixed-Culture Campylobacter jejuni biofilms. Appl. Environ. Microbiol. 2011, 78, 1033-1038. [CrossRef]

8. Zimmer, M.; Barnhart, H.; Idris, U.; Lee, M.D. Detection of Campylobacter jejuni strains in the water lines of a commercial broiler house and their relationship to the strains that colonized the chickens. Avian Dis. 2003, 47, 101-107. [CrossRef]

9. Joshua, G.W.P.; Guthrie-Irons, C.; Karlyshev, A.V.; Wren, B.W. Biofilm formation in Campylobacter jejuni. Microbiology 2006, 152, 387-396. [CrossRef]

10. Bronowski, C.; James, C.E.; Winstanley, C. Role of environmental survival in transmission of Campylobacter jejuni. FEMS Microbiol. Lett. 2014, 356, 8-19. [CrossRef]

11. Moore, J.E.; Barton, M.D.; Blair, I.S.; Corcoran, D.; Dooley, J.S.; Fanning, S.; Kempf, I.; Lastovica, A.J.; Lowery, C.J.; Matsuda, M.; et al. The epidemiology of antibiotic resistance in Campylobacter. Microbes Infect. 2006, 8, 1955-1966. [CrossRef]

12. Smith, J.L.; Fratamico, P.M. Fluoroquinolone resistance in Campylobacter. J. Food Prot. 2010, 73, 1141-1152. [CrossRef] [PubMed]

13. World Health Organization, WHO. WHO Publishes List of Bacteria for Which New Antibiotics Are Urgently Needed. Available online: https://www.who.int/news/item/27-02-2017-who-publishes-list-of-bacteria-forwhich-new-antibiotics-are-urgently-needed (accessed on 20 November 2020).

14. Alfredson, D.A.; Korolik, V. Antibiotic resistance and resistance mechanisms in Campylobacter jejuni and Campylobacter coli. FEMS Microbiol. Lett. 2007, 277, 123-132. [CrossRef] [PubMed]

15. Miflin, J.K.; Templeton, J.M.; Blackall, P.J. Antibiotic resistance in Campylobacter jejuni and Campylobacter coli isolated from poultry in the South-East Queensland region. J. Antimicrob. Chemother. 2007, 59, 775-778. [CrossRef] [PubMed]

16. Tambur, Z.; Miljkovic-Selimovic, B.; Bokonjic, D. Determination of sensitivity to antibiotics of Campilobacter jejuni and Campilobacter coli isolated from human feces. Vojn. Pregl. 2009, 66, 49-52. [CrossRef]

17. Sharma, D.; Misba, L.; Khan, A.U. Antibiotics versus biofilm: An emerging battleground in microbial communities. Antimicrob. Resist. Infect. Control. 2019, 8, 1-10. [CrossRef]

18. Kaplan, J. Biofilm Dispersal: Mechanisms, clinical implications, and potential therapeutic uses. J. Dent. Res. 2010, 89, 205-218. [CrossRef]

19. Sauer, K.; Cullen, M.C.; Rickard, A.H.; Zeef, L.A.H.; Davies, D.G.; Gilbert, P. Characterization of nutrient-induced dispersion in Pseudomonas aeruginosa PAO1 biofilm. J. Bacteriol. 2004, 186, 7312-7326. [CrossRef]

20. Rumbaugh, K.P.; Ahmad, I. Antibiofilm Agents: From Diagnosis to Treatment and Prevention, 1st ed.; Rumbaugh, K.P., Ahmad, I., Eds.; Springer: Berlin/Heidelberg, Germany, 2014; Volume 8.

21. Nahar, S.; Mizan, F.R.; Ha, A.J.-W.; Ha, S.-D. Advances and future prospects of enzyme-based biofilm prevention approaches in the food industry. Compr. Rev. Food Sci. Food Saf. 2018, 17, 1484-1502. [CrossRef]

22. Brandenburg, K.S.; Rodriguez, K.J.; McAnulty, J.F.; Murphy, C.J.; Abbott, N.L.; Schurr, M.J.; Czuprynski, C.J. Tryptophan inhibits biofilm formation by Pseudomonas aeruginosa. Antimicrob. Agents Chemother. 2013, 57, 1921-1925. [CrossRef]

23. Vlamakis, H.; Chai, Y.; Beauregard, P.B.; Losick, R.; Kolter, R. Sticking together: Building a biofilm the Bacillus subtilis way. Nat. Rev. Genet. 2013,11, 157-168. [CrossRef]

24. Leiman, S.A.; May, J.M.; Lebar, M.D.; Kahne, D.; Kolter, R.; Losick, R. D-Amino acids indirectly inhibit biofilm formation in Bacillus subtilis by interfering with protein synthesis. J. Bacteriol. 2013, 195, 5391-5395. [CrossRef] [PubMed]

25. Xu, H.; Liu, Y. Reduced microbial attachment by d-amino acid-inhibited AI-2 and EPS production. Water Res. 2011, 45, 5796-5804. [CrossRef] [PubMed]

26. Zilm, P.; Butnejski, V.; Rossi-Fedele, G.; Kidd, S.P.; Edwards, S.; Vasilev, K. D-amino acids reduce Enterococcus faecalis biofilms in vitro and in the presence of antimicrobials used for root canal treatment. PLoS ONE 2017, 12, e0170670. [CrossRef] [PubMed]

27. Aliashkevich, A.; Alvarez, L.; Cava, F. New Insights into the mechanisms and biological roles of D-Amino Acids in complex eco-systems. Front. Microbiol. 2018, 9, 683. [CrossRef] [PubMed] 
28. Azua, I.; Goiriena, I.; Baña, Z.; Iriberri, J.; Unanue, M. Release and consumption of d-amino acids during growth of marine prokaryotes. Microb. Ecol. 2013, 67, 1-12. [CrossRef] [PubMed]

29. Rendueles, O.; Ghigo, J.-M. Multi-species biofilms: How to avoid unfriendly neighbors. FEMS Microbiol. Rev. 2012, 36, 972-989. [CrossRef]

30. Lam, H.; Oh, D.-C.; Cava, F.; Takacs, C.N.; Clardy, J.; de Pedro, M.A.; Waldor, M.K. D-amino acids govern stationary phase cell wall remodeling in bacteria. Science 2009, 325, 1552-1555. [CrossRef]

31. Flemming, H.-C.; Wingender, J. The biofilm matrix. Nat. Rev. Microbiol. 2010, 8, 623-633. [CrossRef]

32. Kostakioti, M.; Hadjifrangiskou, M.; Hultgren, S.J. Bacterial biofilms: Development, dispersal, and therapeutic strategies in the dawn of the postantibiotic Era. Cold Spring Harb. Perspect. Med. 2013, 3, a010306. [CrossRef]

33. Zhang, Z.; Li, Z.; Jiao, N. Effects of d-Amino Acids on the EPS production and cell aggregation of Alteromonas macleodii Strain JL2069. Curr. Microbiol. 2014, 68, 751-755. [CrossRef]

34. Cava, F.; Lam, H.; De Pedro, M.A.; Waldor, M.K. Emerging knowledge of regulatory roles of d-amino acids in bacteria. Cell. Mol. Life Sci. 2011, 68, 817-831. [CrossRef] [PubMed]

35. Ramón-Peréz, M.L.; Diaz-Cedillo, F.; Ibarra, J.A.; Torales-Cardeña, A.; Rodríguez-Martínez, S.; Jan-Roblero, J.; Cancino-Diaz, M.E.; Cancino-Diaz, J.C. D-Amino acids inhibit biofilm formation in Staphylococcus epidermidis strains from ocular infections. J. Med. Microbiol. 2014, 63, 1369-1376. [CrossRef] [PubMed]

36. Hochbaum, A.I.; Kolodkin-Gal, I.; Foulston, L.; Kolter, R.; Aizenberg, J.; Losick, R. Inhibitory Effects of D-amino acids on Staphylococcus aureus biofilm development. J. Bacteriol. 2011, 193, 5616-5622. [CrossRef] [PubMed]

37. Lark, C.; Lark, K.G. Studies on the mechanism by which d-amino acids block cell wall synthesis. Biochim. Biophys. Acta. 1961, 49, 308-322. [CrossRef]

38. Moulder, J.W.; Novosel, D.L.; Officer, J.E. Inhibition of the growth of agents of the psittacosis group by $\mathrm{d}$-cycloserine and its specific reversal by d-alanine. J. Bacteriol. 1963, 85, 707-711. [CrossRef] [PubMed]

39. Awasthy, D.; Bharath, S.; Subbulakshmi, V.; Sharma, U. Alanine racemase mutants of Mycobacterium tuberculosis require d-alanine for growth and are defective for survival in macrophages and mice. Microbiology 2012, 158, 319-327. [CrossRef]

40. Samie, A.; Ramalivhana, J.; Igumbor, E.; Obi, C. Prevalence, haemolytic and haemagglutination activities and antibiotic susceptibility profiles of Campylobacter spp. isolated from human diarrhoeal stools in vhembe district, South Africa. J. Health Popul. Nutr. 2007, 25, 406-413.

41. Kolodkin-Gal, I.; Romero, D.; Cao, S.; Clardy, J.; Kolter, R.; Losick, R. D-amino acids trigger biofilm disassembly. Science 2010, 328, 627-629. [CrossRef]

42. Van Der Hooft, J.J.J.; Alghefari, W.; Watson, E.; Everest, P.; Morton, F.R.; Burgess, K.E.V.; Smith, D.G.E. Unexpected differential metabolic responses of Campylobacter jejuni to the abundant presence of glutamate and fucose. Metabolomics 2018, 14, 144. [CrossRef]

43. Sanchez, C.J., Jr.; Akers, K.S.; Romano, D.R.; Woodbury, R.L.; Hardy, S.K.; Murray, C.K.; Wenke, J.C. D-amino acids enhance the activity of antimicrobials against biofilms of clinical wound isolates of Staphylococcus aureus and Pseudomonas aeruginosa. Antimicrob. Agents Chemother. 2014, 58, 4353-4361. [CrossRef]

44. Wijsman, H.J.W. The characterization of an alanine racemase mutant of Escherichia coli. Genet. Res. 1972, 20, 269-277. [CrossRef] [PubMed]

45. Sidiq, K.R.; Chow, M.W.; Zhao, Z.; Daniel, R.A. Alanine metabolism in Bacillus subtilis. Mol. Microbiol. 2020, 562850. [CrossRef] [PubMed]

46. Turonova, H.; Neu, T.R.; Ulbrich, P.; Pazlarova, J.; Tresse, O. The biofilm matrix of Campylobacter jejuni determined by fluorescence lectin-binding analysis. Biofouling 2016, 32, 597-608. [CrossRef] [PubMed]

47. Cava, F.; de Pedro, M.A.; Lam, H.; Davis, B.M.; Waldor, M.K. Distinct pathways for modification of the bacterial cell wall by non-canonical D-amino acids. EMBO J. 2011, 30, 3442-3453. [CrossRef] [PubMed]

48. Mandal, R.K.; Jiang, T.; Kwon, Y.M. Essential genome of Campylobacter jejuni. BMC Genom. 2017, 18 , 1-14. [CrossRef] [PubMed]

49. Gao, B.; Lara-Tejero, M.; Lefebre, M.; Goodman, A.L.; Galán, J.E. Novel components of the flagellar system in epsilonproteobacteria. mBio 2014, 5, e01349-14. [CrossRef]

50. Chacon, O.; Bermudez, L.E.; Zinniel, D.K.; Chahal, H.K.; Fenton, R.J.; Feng, Z.; Hanford, K.; Adams, L.G.; Barletta, R.G. Impairment of d-alanine biosynthesis in Mycobacterium smegmatis determines decreased intracellular survival in human macrophages. Microbiology 2009, 155, 1440-1450. [CrossRef] 
51. Qiu, W.; Zheng, X.; Wei, Y.; Zhou, X.; Zhang, K.; Wang, S.; Cheng, L.; Li, Y.; Ren, B.; Xu, X.; et al. D-Alanine metabolism is essential for growth and biofilm formation of Streptococcus mutans. Mol. Oral Microbiol. 2016, 31, 435-444. [CrossRef] [PubMed]

52. Wei, Y.; Qiu, W.; Zhou, X.-D.; Zheng, X.; Zhang, K.-K.; Wang, S.-D.; Li, Y.-Q.; Cheng, L.; Li, J.-Y.; Xu, X.; et al. Alanine racemase is essential for the growth and interspecies competitiveness of Streptococcus mutans. Int. J. Oral Sci. 2016, 8, 231-238. [CrossRef]

53. Batson, S.; Rea, D.; Fülöp, V.; Roper, D.I. Crystallization and preliminary X-ray analysis of a D-alanyl-D-alanine ligase (EcDdlB) from Escherichia coli. Acta Crystallogr. Sect. F Struct. Biol. Cryst. Commun. 2010, 66, 405-408. [CrossRef]

54. Halouska, S.; Fenton, R.J.; Zinniel, D.K.; Marshall, D.D.; Barletta, R.G.; Powers, R. Metabolomics Analysis Identifiesd-Alanine-d-Alanine Ligase as the Primary Lethal Target of d-Cycloserine in Mycobacteria. J. Proteome Res. 2014, 13, 1065-1076. [CrossRef] [PubMed]

55. Van Der Aart, L. Lizah T.; Lemmens, N.; Van Wamel, W.J.; Van Wezel, G.P. Substrate inhibition of VanA by d-Alanine reduces vancomycin resistance in a VanX-dependent manner. Antimicrob. Agents Chemother. 2016, 60, 4930-4939. [CrossRef] [PubMed]

56. Healy, V.L.; Lessard, I.A.; Roper, D.I.; Knox, J.R.; Walsh, C.T. Vancomycin resistance in enterococci: Reprogramming of the d-Ala-d-Ala ligases in bacterial peptidoglycan biosynthesis. Chem. Biol. 2000, 7, R109-R119. [CrossRef]

57. A Lessard, I.; Healy, V.L.; Park, I.S.; Walsh, C.T. Determinants for differential effects on D-Ala-D-lactate vs D-Ala-D-Ala formation by the VanA ligase from vancomycin-resistant enterococci. Biochemistry 1999, 38, 14006-14022. [CrossRef] [PubMed]

58. Lebreton, F.; Depardieu, F.; Bourdon, N.; Fines-Guyon, M.; Berger, P.; Camiade, S.; Leclercq, R.; Courvalin, P.; Cattoir, V. D-Ala-d-Ser VanN-Type transferable vancomycin resistance in Enterococcus faecium. Antimicrob. Agents Chemother. 2011, 55, 4606-4612. [CrossRef] [PubMed]

59. Tram, G.; Korolik, V.; Day, C.J. MBDS Solvent: An Improved method for assessment of biofilms. Adv. Microbiol. 2013, 3, 200-204. [CrossRef]

60. Singh, N.; Patil, A.; Prabhune, A.; Goel, G. Inhibition of quorum-sensing-mediated biofilm formation in Cronobacter sakazakii strains. Microbiology 2016, 162, 1708-1714. [CrossRef] [PubMed]

61. Bai, J.; Wu, Y.; Elena, G.; Zhong, K.; Gao, H. Insight into the effect of quinic acid on biofilm formed by Staphylococcus aureus. RSC Adv. 2019, 9, 3938-3945. [CrossRef]

62. Day, C.J.; E Hartley, L.; Shewell, L.K.; King, R.M.; Tram, G.; Day, S.K.; Semchenko, E.A.; Korolik, V. Variation of chemosensory receptor content of Campylobacter jejuni strains and modulation of receptor gene expression under different in vivo and in vitro growth conditions. BMC Microbiol. 2012, 12, 128. [CrossRef]

63. Schmittgen, T.D.; Livak, K.J. Analyzing real-time PCR data by the comparative CT method. Nat. Protoc. 2008, 3, 1101-1108. [CrossRef]

64. Schefe, J.H.; Lehmann, K.E.; Buschmann, I.R.; Unger, T.; Funke-Kaiser, H. Quantitative real-time RT-PCR data analysis: Current concepts and the novel "gene expression's C T difference" formula. J. Mol. Med. 2006, 84, 901-910. [CrossRef] [PubMed]

65. Peeters, E.; Nelis, H.J.; Coenye, T. Comparison of multiple methods for quantification of microbial biofilms grown in microtiter plates. J. Microbiol. Methods 2008, 72, 157-165. [CrossRef] [PubMed]

66. Khurana, R.; Coleman, C.; Ionescu-Zanetti, C.; Carter, S.A.; Krishna, V.; Grover, R.K.; Roy, R.; Singh, S. Mechanism of thioflavin-T binding to amyloid fibrils. J. Struct. Biol. 2005, 151, 229-238. [CrossRef] [PubMed]

67. Biancalana, M.; Koide, S. Molecular mechanism of Thioflavin-T binding to amyloid fibrils. Biochim. Biophys. Acta 2010, 1804, 1405-1412. [CrossRef] [PubMed]

Publisher's Note: MDPI stays neutral with regard to jurisdictional claims in published maps and institutional affiliations. 